Article

\title{
Evaluation of Water Circulation by Modeling: An Example of Nonpoint Source Management in the Yeongsan River Watershed
}

\author{
Jong Mun Lee, Minji Park, Bae Kyung Park *, Jiyeon Choi, Jinsun Kim, Kyunghyun Kim (D) and Yongseok Kim
}

check for

updates

Citation: Lee, J.M.; Park, M.; Park, B.K.; Choi, J.; Kim, J.; Kim, K.; Kim, Y. Evaluation of Water Circulation by Modeling: An Example of Nonpoint Source Management in the Yeongsan River Watershed. Sustainability 2021, 13, 8871. https://doi.org/10.3390/ su13168871

Academic Editors: Sung Min Cha and Fernando António Leal Pacheco

Received: 24 June 2021

Accepted: 29 July 2021

Published: 9 August 2021

Publisher's Note: MDPI stays neutral with regard to jurisdictional claims in published maps and institutional affiliations.

Copyright: (C) 2021 by the authors Licensee MDPI, Basel, Switzerland. This article is an open access article distributed under the terms and conditions of the Creative Commons Attribution (CC BY) license (https:// creativecommons.org/licenses/by/ $4.0 /)$.
Water Environmental Research Department, National Institute of Environmental Research (NIER), Incheon 22689, Korea; leejm0909@korea.kr (J.M.L.); iamg79@korea.kr (M.P.); yeonjichoi@korea.kr (J.C.); kjs1235@korea.kr (J.K.); matthias@korea.kr (K.K.); nierkys@korea.kr (Y.K.)

* Correspondence: bkpark67@korea.kr; Tel.: +82-32-560-7385

\begin{abstract}
Owing to urbanization, impervious areas within watersheds have continuously increased, distorting healthy water circulation systems by reducing soil infiltration and base flow; moreover, increases in surface runoff deteriorate water quality by increasing the inflow of nonpoint sources. In this study, we constructed a Hydrological Simulation Program-Fortran (HSPF) watershed model that applies the impervious area and can set medium- and long-term water circulation management goals for watershed sub-areas. The model was tested using a case study from the Yeongsan River watershed, Korea. The results show that impervious land-cover accounts for $18.47 \%$ of the upstream reach in which Gwangju City is located; approximately twice the average for the whole watershed. Depending on the impervious area reduction scenario, direct runoff and nonpoint source load could be reduced by up to $56 \%$ and $35 \%$, respectively; the water circulation rate could be improved by up to $16 \%$. Selecting management goals requires the consideration of both policy objectives and budget. For urban areas with large impervious cover, the designation of nonpoint source management areas is required. For new cities, it is necessary to introduce water circulation systems (e.g., low impact development techniques) to improve rainwater penetration and recharge and activate preemptive water circulation.
\end{abstract}

Keywords: impervious area; nonpoint sources; HSPF watershed model; direct runoff; water circulation rate; water circulation management goal

\section{Introduction}

Owing to advances in land use and an increase in economic activities, the impervious area has continuously increased in South Korea, rising to 7.7\% in 2017 (2.6 times higher than in the 1970s). Seoul exhibited the highest rate $(52.8 \%)$, and most metropolitan cities showed a rate of more than $20 \%$ [1]. Urbanization exerts considerable influence on regional hydrological balances [2,3]. An increase in the impervious area causes a reduction in soil penetration and base flow, which distorts the healthy water circulation system; meanwhile, increased surface runoff deteriorates water quality by increasing the inflow of nonpoint sources [4]. Agricultural irrigation and deforestation for urbanization can lead to the occurrence of natural disasters [5]. For example, studies have shown that the improvement of natural streams to expand urban areas increases the risk of flooding [6,7]. This issue is further exacerbated by unprecedented rainfall patterns and an increase in annual average temperature under the influence of climate change [1,8]. In summary, there is an increasing need to manage the impervious area.

In Korea, the government is pursuing the construction of a sustainable water circulation system to improve impervious surface and water circulation management. It has set water circulation management goals (impervious area rate and water circulation rate) for the country, and has established comprehensive countermeasures for nonpoint 
source management by revising the Water Environment Conservation Act of 2018. The government has also reviewed the planning and implementation of policies to achieve such goals [4]. As the water circulation goals of the third comprehensive countermeasures for nonpoint source management ('21 to '25), the impervious area rate and water circulation rate were set for 17 metropolitan areas and 818 smaller areas across the country. In addition, for watersheds where the impervious area rate exceeds $25 \%$, medium- and long-term management goals for the recovery of water circulation have been proposed [9].

A number of studies have considered the role of impervious pavement in water circulation. Shiqiang et al. [10] analyzed the influence of impervious surfaces during flooding in the Longhua watershed in China. They derived the major subwatersheds that affected the amount of flooding by introducing the concept of the Impervious Surface Impact Index. Aditi [11] presented the relationships among watershed water circulation elements, such as the base flow, storm flow, and evapotranspiration, considering changes in surface cover and pavement, including vegetation cover, as well as urbanization and the impervious area. Gerhard [12] analyzed the influence of impervious surfaces on heavy rain events with low precipitation. Impervious areas were divided into those connected to drainage and those not connected to drainage, and it was found that runoff under low precipitation was caused by the former alone. Apollonio et al. [13] studied the effect of spatiotemporal changes in land use and land cover in the hydrological regime of the Cervaro Basin in southern Italy. Lands change maps were generated for 28 years from 1984 to 2011 through LANDSAT Thematic Mapper (TM) images. As a result of the analysis, between 1984 and 2011, the peak of flooding increased and the grazing land and forest decreased. It shows a good correlation between flood area and land use change. It also shows that the impact of land use on the hydrological response is closely related to the watershed size. Chunlin et al. [14] predicted the amount of runoff due to changes in land use based on the CN (Curve Number) method. They analyzed the tendency of direct runoff by size from 1984 to 2015, and reported that the increase in impervious surface area owing to urbanization is the most direct cause of the increase in direct runoff. Lee et al. [4] applied a Hydrological Simulation Program-Fortran (HSPF) watershed model to the Geum River watershed in Korea and analyzed changes in the flow and water quality of the watershed due to changes in land use. They also analyzed changes in direct runoff and nonpoint source load according to the impervious area reduction scenario, and attempted to analyze the current status of the watershed and the reduction effect by deriving the water circulation rate.

In terms of the relationships among impervious area, water quality, and aquatic ecosystems, Kim et al. [15] set an impermeable area rate of 5-15\% as the level of "good water" in the river water quality criteria. They proposed that this can be used as an impervious surface management criterion for the purpose of the water quality environment. KunLuo et al. [16] evaluated the influence of urbanization on river water quality and aquatic ecosystems in the Liangjiang New Area. They confirmed that urbanization increased nutrient concentrations in rivers and the river flow. They also reported that the invertebrate population significantly changed over three levels of urbanization. Yi et al. [17] analyzed the correlation between the impervious area and lake water quality in the Dianchi Lake watershed. The impervious area increased from $1.84 \%$ in 1988 to $34.32 \%$ in 2017 . They reported that there were significant correlations among the impervious area, chlorophyll-a, and dissolved oxygen during this period.

Although there have been various studies on impervious surfaces and water circulation, few have identified the relationship between management factors. In addition, quantitative indicators for setting water circulation management goals and evaluating the improvement effect are required for each watershed. Previous studies on water circulation management indicators have focused on facility evaluation to help manage rainwater and improve water circulation in the event of a single rainfall event for an urban area. Therefore, research on the analysis of water circulation systems and the calculation of management indicators for a given target area with various land uses within the watershed is required. 
The purpose of this study was to construct a watershed model that can identify the relationships among the land use (impervious area), river water quality, and flow. Using this model, we set medium- and long-term water circulation management goals for subareas of the Yeongsan River watershed using various impervious area reduction scenarios and principles for setting water circulation management goals.

\section{Materials and Methods}

\subsection{Study Area}

This study was conducted for the Yeongsan River watershed in Korea (Figure 1). The total watershed area is $3469.58 \mathrm{~km}^{2}$. The water resource unit map was standardized by the ME (Ministry of Environment) and MOLIT (Ministry of Land, Infrastructure and Transport). Based on this, it is split into 8 medium-sized areas containing a total of 34 smaller areas (Table 1). It has a total river length of $1083.04 \mathrm{~km}$ and a river length of $129.5 \mathrm{~km}$, and consists of five national rivers and 163 local rivers. The middle and upstream areas contain densely populated areas, such as Gwangju and Naju cities [18]. The watershed includes four of the largest agricultural reservoirs in Korea (Lake Jangseong, Lake Naju, Lake Damyang, and Lake Gwangju); their total effective storage capacity is approximately $240,000,000 \mathrm{~m}^{3}$, representing $9 \%$ of the area of the Yeongsan River watershed [19]. Owing to a large river project in 2012, two weirs (Seungchon and Juksan) are in operation. The area-averaged annual precipitation of the three major weather stations (Namwon, Imsil, and Gwangju) is $1277.4 \mathrm{~mm}$. The Jiseok Stream sub-area has the highest annual precipitation (1), while the Yeongsan River Estuary sub-area has the lowest annual precipitation (1088.7 mm) [20]. The total land area of the watershed is approximately $3469.58 \mathrm{~km}^{2}$ (as of 2017). Forests and fields represent the highest proportion (50.7\%), followed by farmland (28.7\%) and buildings (9.9\%) [21]. Over the last five years, the proportions of forests, paddies, and upland fields have decreased, whereas building cover has continuously increased.

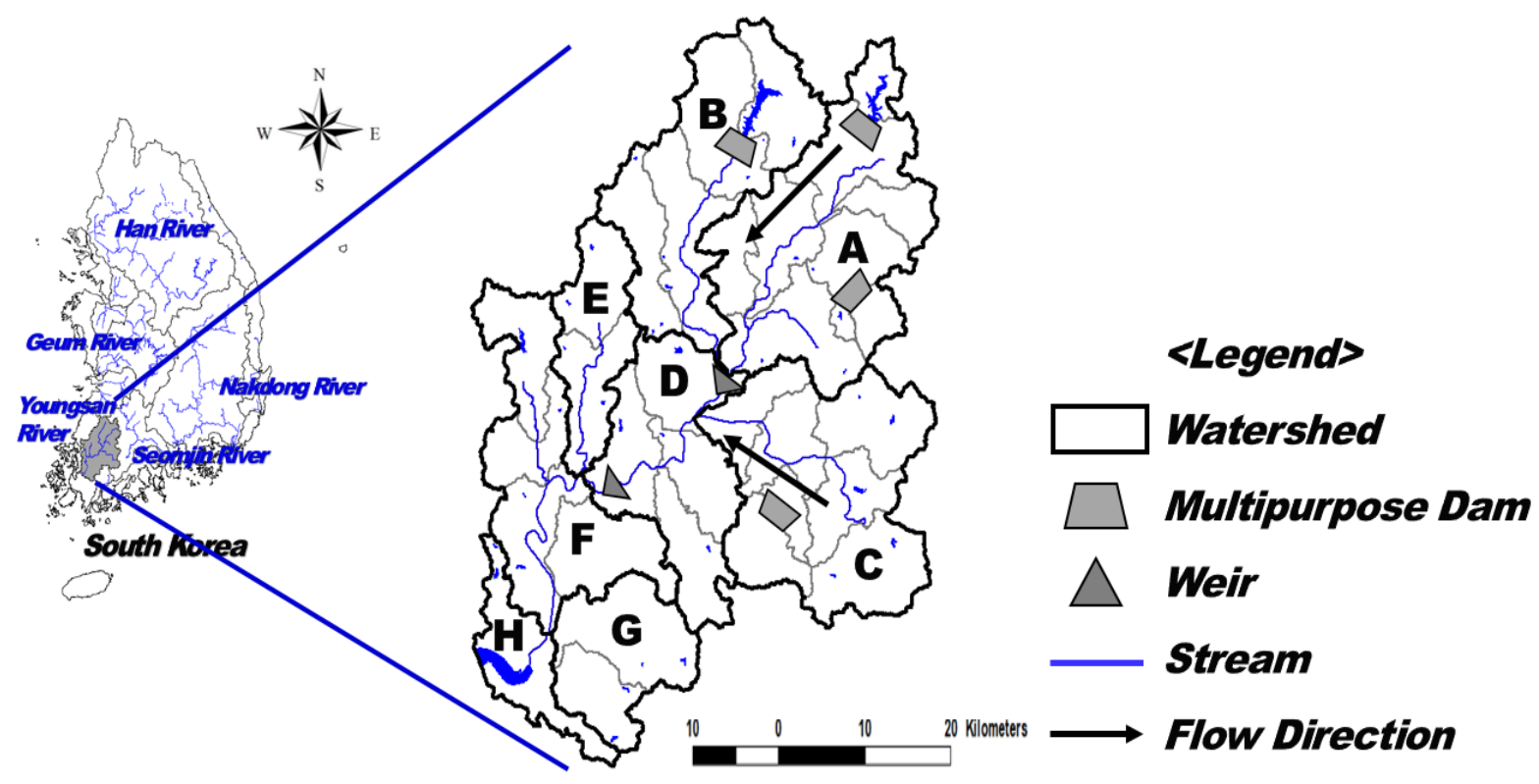

Figure 1. Study area map (Yeongsan River watershed). 
Table 1. Medium-sized sub-areas of the Yeongsan River watershed.

\begin{tabular}{cccc}
\hline Watershed & Sub-Area & $\begin{array}{c}\text { Area } \\
\mathbf{( k m}^{\mathbf{2}} \mathbf{)}\end{array}$ & $\begin{array}{c}\text { Number of } \\
\text { Small Areas }\end{array}$ \\
\hline A & Upper Yeongsan River & 718.59 & 8 \\
B & Hwangryong River & 565.64 & 4 \\
C & Jiseok Stream & 664.93 & 7 \\
D & Juksan Weir & 408.56 & 5 \\
E & Gomakwon Stream & 219.49 & 2 \\
F & Lower Yeongsan River & 484.93 & 4 \\
G & Yeongam Stream & 265.52 & 2 \\
H & Yeongsan River Estuary & 147.91 & 2 \\
\hline
\end{tabular}

\subsection{Model Selection}

The same analysis model and input data as those used by NIER [22] and Lee et al. [4] were used in this study. The watershed model was HSPF, which was developed by the U.S. Environmental Protection Agency (US EPA) to simulate various complex phenomena associated with water hydraulics and water quality occurring over an extended period of time in a watershed. It consists of the three major application modules to simulate hydrological phenomena and water quality within the pervious layer (PERLND), impervious layer (IMPLND), and river (RCHRES) [23].

\subsection{Input Data Construction}

The HSPF model requires data inputs that include a map of the watershed, a digital elevation model (DEM), a land cover map, and a river map (Table 2). Spatial information for the Yeongsan River watershed model was constructed based on 34 small areas as the minimum units. Among the input data, the land cover map used land use data of the Korea Environment Corporation (K-eco) [24], which reflects the latest impervious area information (as of 2017). The river map was constructed based on the Korea Reach File (KRF) 3.0 of the ME. For meteorological data, a Thiessen polygon was constructed using the locations of automated synoptic observing systems of the Korea Meteorological Administration (KMA), and four weather stations (Jeongeup, Gwangju, Suncheon, and Mokpo) that affect the small areas. In addition, data on 16 meteorological items (including precipitation, maximum temperature, minimum temperature, wind speed, solar irradiation, and dew point temperature) were applied to the model. For basic environmental facilities with a capacity of 1000 tons/day or more for point sources of national discharge loads (e.g., domestic, livestock, and land pollutant loads) from 2013 to 2017, the outflow and discharge water quality (BOD (Biochemical Oxygen Demand), T-N (Total Nitrogen), and T-P (Total Phosphorus)) were applied; this excluded linked treatment facilities. Since the Yeongsan River has four large agricultural reservoirs, we applied outflow data from the Korea Rural Community Corporation (KR). In addition, data from two weirs were constructed in the same manner. Finally, the water intake data for regional and local water supply systems in the study area were acquired and entered into the model (Table 2).

The T-P water quality was chosen as the simulated item as it can represent the flow of rivers and nonpoint source runoff characteristics of urban areas. In the watershed unit, direct runoff was introduced into the river and the T-P nonpoint source load was simulated. 
Table 2. Input data for watershed model construction [4].

\begin{tabular}{|c|c|c|c|}
\hline Data & Analysis Items & Scale & Reference \\
\hline DEM & Digital Elevation Model $(30 \times 30$ m) & $1: 5000$ & $\begin{array}{l}\text { National Geographic } \\
\text { Information Institute }\end{array}$ \\
\hline Land-use & $\begin{array}{c}\text { Land cover classification (Urban, } \\
\text { Agriculture, Forest, Pasture, Water, } \\
\text { Wetland, Barren land) }\end{array}$ & $1: 25,000$ & K-eco \\
\hline Weather data & $\begin{array}{l}16 \text { items (e.g., Rainfall, Average } \\
\text { temperature, Dew point, Solar } \\
\text { radiation, Wind speed) }\end{array}$ & $\begin{array}{c}\text { Hourly } \\
\text { (2004 2017 year) }\end{array}$ & KMA \\
\hline \multirow[t]{2}{*}{ Hydrological } & $\begin{array}{c}\text { Discharge Flow (Reservoirs } \\
\text { (Jangseong, Naju, Gwangju, } \\
\text { Damyang)) and Weir (Sejong, } \\
\text { Gongju, Baekje)) }\end{array}$ & \multirow[t]{2}{*}{8 day/month } & \multirow[t]{2}{*}{$\begin{array}{c}\text { KR } \\
\text { WAMIS/Water Environment } \\
\text { Information System }\end{array}$} \\
\hline & $\begin{array}{l}\text { Automatic and Water } \\
\text { Environment Network }\end{array}$ & & \\
\hline Water Quality & Water Environment Network (TP) & 8 day/month & $\begin{array}{l}\text { Water Environment } \\
\text { Information System }\end{array}$ \\
\hline $\begin{array}{l}\text { Environmental Foundational } \\
\text { Facilities }\end{array}$ & $\begin{array}{c}\text { Flow, BOD, TAM, NO3, ORN, } \\
\text { PO4, ORP }\end{array}$ & Daily & NIER \\
\hline Pollutant Loads & BOD, TAM, NO3, ORN, PO4, ORP & Daily & NIER \\
\hline Administration boundary & Catchment basin map & - & ME \\
\hline
\end{tabular}

To increase the accuracy of prediction, calibration and validation (calibration period: 5 years; validation period: 5 years) were performed by adjusting the parameters related to the flow and water quality. To evaluate the accuracy of calibration and validation, the flow was evaluated using $R^{2}$ and the average relative error (\%Difference) between the simulated and measured values; the water quality was evaluated using the average relative error. For flow and water quality, water environment network data of the research area provided by the Water Environment Information System were used. In addition, evaluation criteria suggested by Donigian [25] and US EPA [26] (Table 3) were applied using the trial and error method. Calibration and validation were performed by selecting parameters that can adjust the flow, and which may affect the total runoff, surface runoff, base flow, and water quality concentrations of BOD, T-N, and T-P in the river.

Table 3. Evaluation criteria for validation of model parameters.

\begin{tabular}{cccccc}
\hline \multicolumn{2}{c}{ Constituent } & Very Good & Good & Fair & Poor \\
\hline Hydrology/Flow & $\mathrm{R}^{2}$ & $>0.8$ & $0.7 \sim 0.8$ & $0.6 \sim 0.7$ & $>0.6$ \\
10 Difference & $<10$ & $15 \sim 15$ & $15 \sim 25$ & $<25$ \\
\hline $\begin{array}{c}\text { Water Qual- } \\
\text { ity/Nutrients }\end{array}$ & \% Difference & $<15$ & $15 \sim 25$ & $25 \sim 35$ & $<35$ \\
\hline
\end{tabular}

\subsection{Water Circulation and Nonpoint Pollution Status Evaluation}

Water circulation management indicators were defined as the impervious area rate and water circulation rate. Based on the research results of NIER [22] and Lee et al. [4], the impervious area rate was calculated by dividing the impervious area by the total area using the cadastral map, use area map, and continuous digital map, as shown in Equation (1):

$$
\text { Impervious area rate }=(\text { Impervious area } / \text { total area }) \times 100
$$


Water circulation rates were calculated under the single rainfall event condition and long-term rainfall event condition. The water circulation rate under the single rainfall event condition was calculated using the NRCS-CN technique [27], as shown in Equation (2).

$$
\mathrm{S}(\mathrm{mm})=\frac{25400}{C N}-254
$$

where the potential maximum retention (S) is the maximum amount of water that can be retained in the watershed, representing the penetration and storage capacity; and $\mathrm{CN}$ is the runoff curve number. Under the long-term rainfall event condition, the annual direct runoff of the model was used when the direct runoff was calculated in the same process (Equation (3)):

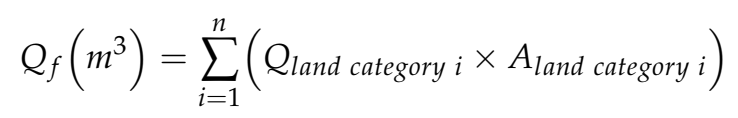

where $Q_{f}$ is the direct runoff, $Q_{\text {land category } i}$ is the direct runoff by land category $\times 10^{-3}(\mathrm{~m})$, and $A_{\text {land category } i}$ is the area by land category $\left(\mathrm{m}^{2}\right)$.

The direct runoff of the target area is given by Equation (4):

$$
R_{f}=\frac{Q_{f}}{P \times A}
$$

where $R_{f}$ is the direct runoff of the target area, $P$ is the total precipitation (mm), and $A$ is the total area of the target area $\left(\mathrm{m}^{2}\right)$.

Finally, the water circulation rate can be calculated using Equation (5):

$$
\text { Water circulation rate }(\%)=\left(1-R_{f}\right) \times 100
$$

\subsection{Analysis of the Water Circulation Structure and Water Quality Improvement}

Based on the water circulation and nonpoint pollution management results for vulnerable areas within each small sub-area, impervious area reduction scenarios were applied. Changes in the annual average direct runoff, base flow, and nonpoint source load reduction effect of the watershed based on a 10-year simulation were simulated for five scenarios. The scenarios were created by referring to the impervious area-watershed health status indicator of previous studies [4,28], as shown in Table 4. Scenario 1 considered the current status and scenario 2 considered naturally increased development. In scenarios 3 and 4 , the impervious area rate was fixed at $35 \%$ and $25 \%$, respectively, for all small areas that exceeded $35 \%$ and $25 \%$, respectively. In scenarios 5 and 6 , the impervious area rate was fixed at $15 \%$ and $5 \%$, respectively, for all small areas that exceeded $15 \%$ and $5 \%$, respectively.

Table 4. Impervious area reduction scenarios.

\begin{tabular}{cc}
\hline $\begin{array}{c}\text { Scenario } \\
\text { S-1 }\end{array}$ & $\begin{array}{c}\text { Description } \\
\text { Current status of the impervious area }\end{array}$ \\
\hline S-2 & $\begin{array}{c}\text { Impervious area status with naturally increased development until } 2025 \\
\text { (including national projects) }\end{array}$ \\
\hline S-3 & Impervious area rate fixed at 35\% for all small areas that exceed $35 \%$ \\
\hline S-4 & Impervious area rate fixed at $25 \%$ for all small areas that exceed $25 \%$ \\
\hline S-5 & Impervious area rate fixed at $15 \%$ for all small areas that exceed $15 \%$ \\
\hline S-6 & Impervious area rate fixed at $5 \%$ for all small areas that exceed $5 \%$ \\
\hline
\end{tabular}

\subsection{Setting Medium- and Long-Term Water Circulation Management Goals}

The medium-term management target period was set to 2025 and the long-term management target period was set to 2065. Management goals for achieving a certain water 
quality level (the impervious area rate and water circulation rate) and other details, such as medium- and long-term management periods, were set mainly for small areas with a high urbanization rate [29] based on the results of various studies [29,30] that analyzed the relationship between the health of the existing watersheds (e.g., water environment and ecosystems) and the impervious area rate. Based on previous work, the health of the watershed was considered to deteriorate when the impervious area rate was $25 \%$ or higher.

We applied an investment plan for the period until 2025 (KRW 73.6 billion) related to water circulation improvement of the Yeongsan River watershed [20] and the unit cost of applying the low impact development (LID) technique per area (KRW 16.6 billion $/ \mathrm{km}^{2}$ ), as described in the master plan of the ME for water circulation in major cities (Table 5). In addition, the status of the impervious area of the watershed considering the characteristics of each watershed (financial independence, impervious area rate, and public facility area rate) was applied to the model. Based on this, water circulation management goals (impervious area rate and water circulation rate) for a certain improvement in water quality (watershed nonpoint source load and river pollutant load) were derived.

Table 5. Average cost of applying the low impact development (LID) technique described in the master plan for water circulation in major cities.

\begin{tabular}{|c|c|c|c|c|c|c|}
\hline Category & Gwangju & Andong & Gimhae & Daejeon & Ulsan & Average \\
\hline Impervious area $\left(\mathrm{km}^{2}\right)$ & 25.74 & 14.23 & 17.84 & 28.31 & 30.51 & 23.33 \\
\hline $\begin{array}{l}\text { Cost of applying the LID technique } \\
\text { (KRW } 100 \text { million) }\end{array}$ & 2813 & 2104 & 3330 & 6217 & 5090 & 3911 \\
\hline $\begin{array}{c}\text { Cost per area } \\
\left(\text { KRW } 100 \text { million } / \mathrm{km}^{2}\right)\end{array}$ & 109 & 148 & 187 & 220 & 167 & 166 \\
\hline
\end{tabular}

\section{Results and Discussion}

\subsection{Watershed Model Construction Results}

Figure 2 shows the data constructed for the watershed and the HSPF model construction results.

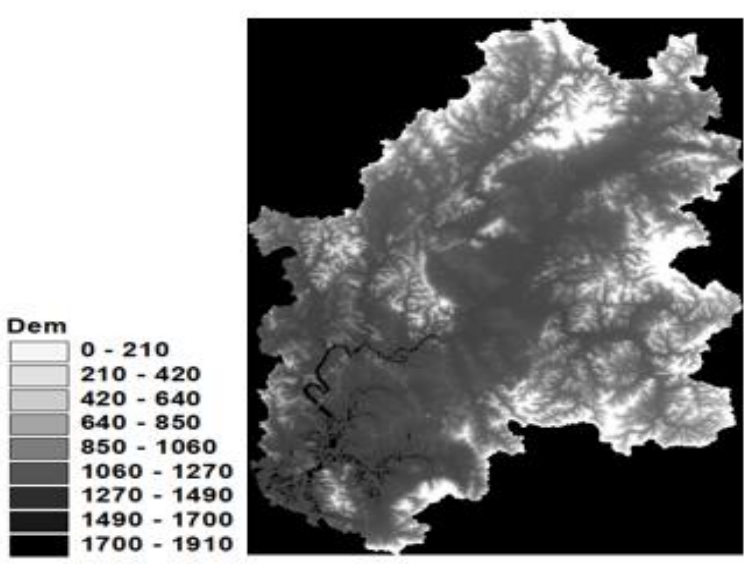

(a) DEM

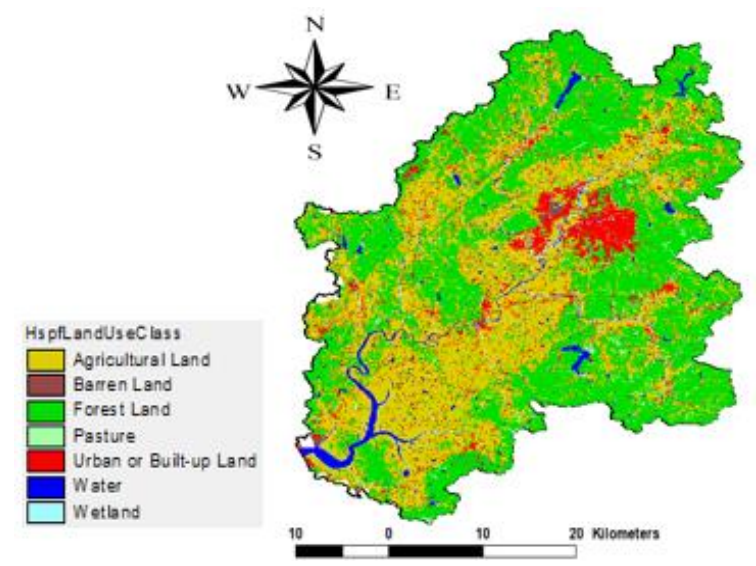

(b) Landuse

Figure 2. Cont. 


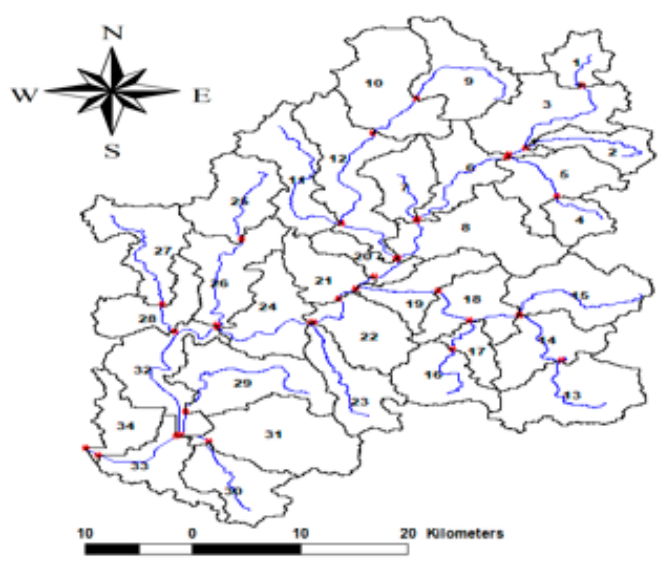

(c) Watershed and Stream
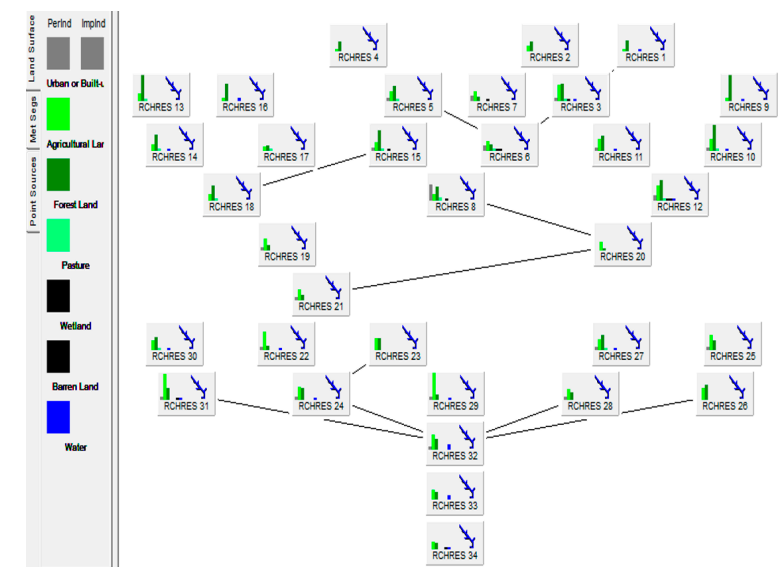

(d) HSPF Model

Figure 2. Input data for the Hydrological Simulation Program-Fortran (HSPF) model and the model construction results. (a) Input digital elevation model (DEM), (b) input land use map, (c) input watershed and stream map, and (d) model output.

The flow and water quality were calibrated and validated by collecting the data of the monitoring network (water environment information system) and the flow and water quality monitoring stations (WAMIS) for four major locations among the eight mediumsized sub-areas. Table 6 shows the parameters applied during the calibration and validation of the flow and water quality. Parameter calibration and validation were performed by comparing the simulated and measured values, as shown in Figure 3.

Table 6. Major parameters of the Hydrological Simulation Program-Fortran (HSPF) model that are related to the flow and water quality.

\begin{tabular}{|c|c|c|c|c|c|}
\hline & Parameter & Description & Unit & Model Range & This Study \\
\hline \multirow{6}{*}{ Flow } & LZSN & $\begin{array}{l}\text { Lower Zone Nominal Soil } \\
\text { Moisture Storage }\end{array}$ & in & $0.01 \sim 100$ & $4.0 \sim 6.5$ \\
\hline & INFILT & Index to Infiltration Capacity & $\mathrm{in} / \mathrm{h}$ & $0.0001 \sim 100$ & $0.2 \sim 0.35$ \\
\hline & AGWRC & Base Groundwater Recession & none & $0.001 \sim 0.999$ & $0.91 \sim 0.98$ \\
\hline & DEEPER & $\begin{array}{c}\text { Fraction of GW inflow to } \\
\text { deep recharge }\end{array}$ & none & $0.0 \sim 1.0$ & $0.001 \sim 0.25$ \\
\hline & INTFW & Interflow inflow parameter & none & $0.0 \sim$ none & $0.75 \sim 10$ \\
\hline & IRC & Interflow recession parameter & none & $0.1 \sim 30.0$ & $0.5 \sim 0.85$ \\
\hline \multirow{5}{*}{$\begin{array}{l}\text { Water } \\
\text { Quality }\end{array}$} & KBOD20 & Unit BOD decay rate at $20^{\circ} \mathrm{C}$ & $1 / \mathrm{h}$ & $0 \sim$ none & $0.001 \sim 0.004$ \\
\hline & KODSET & BOD settling rate & $\mathrm{ft} / \mathrm{h}$ & $0 \sim$ none & $0.001 \sim 0.027$ \\
\hline & KNO220 & Nitrification rates of nitrate at $20^{\circ} \mathrm{C}$ & $1 / \mathrm{h}$ & $0.001 \sim$ none & $0.002 \sim 0.052$ \\
\hline & CVBPC & $\begin{array}{l}\text { Conversion from biomass } \\
\text { expressed as phosphorus to carbon }\end{array}$ & moles/mol & $50 \sim 200$ & $86 \sim 106$ \\
\hline & CVBPN & $\begin{array}{l}\text { Conversion from biomass } \\
\text { expressed as phosphorus } \\
\text { to nitrogen }\end{array}$ & moles $/ \mathrm{mol}$ & $10 \sim 50$ & $10 \sim 16$ \\
\hline
\end{tabular}




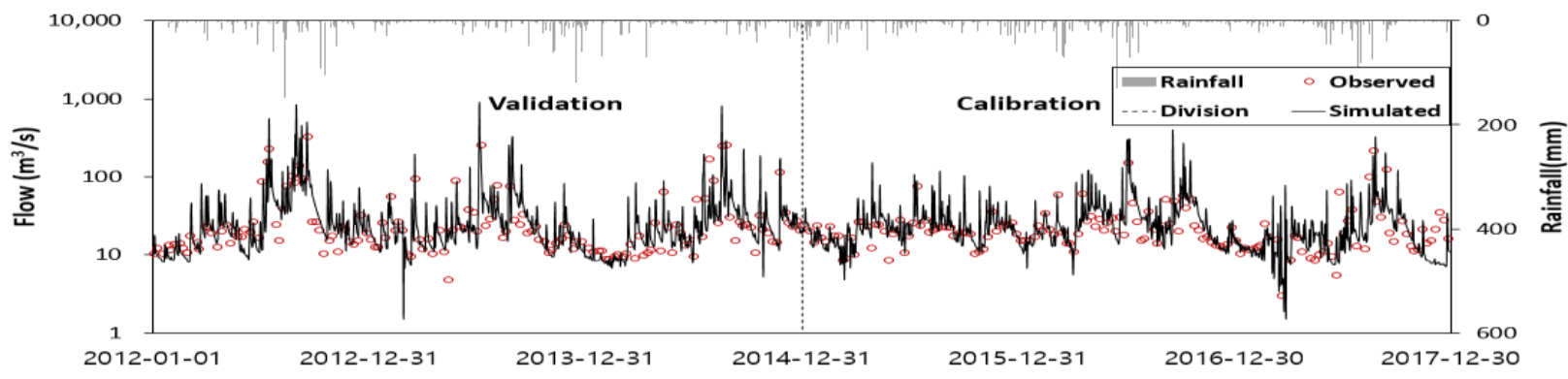

(a-1) Flow

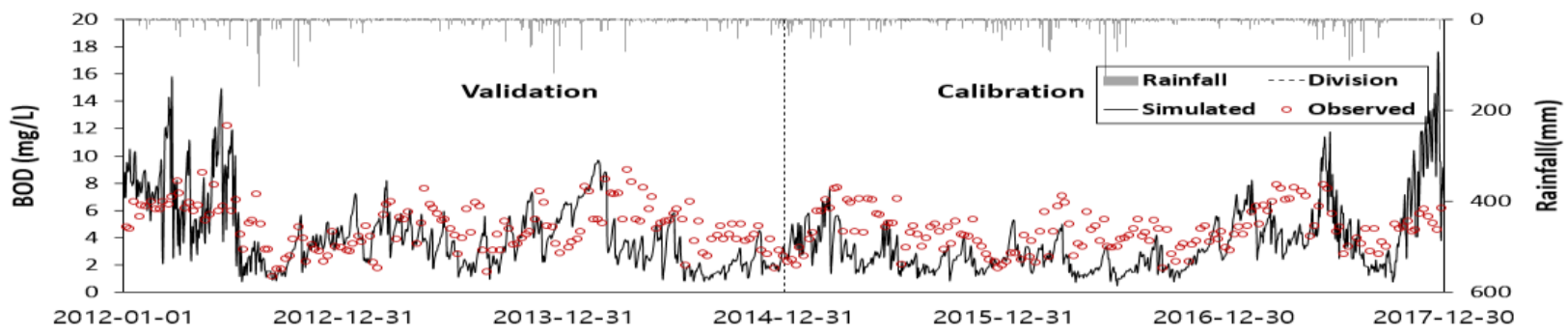

(a-2) BOD

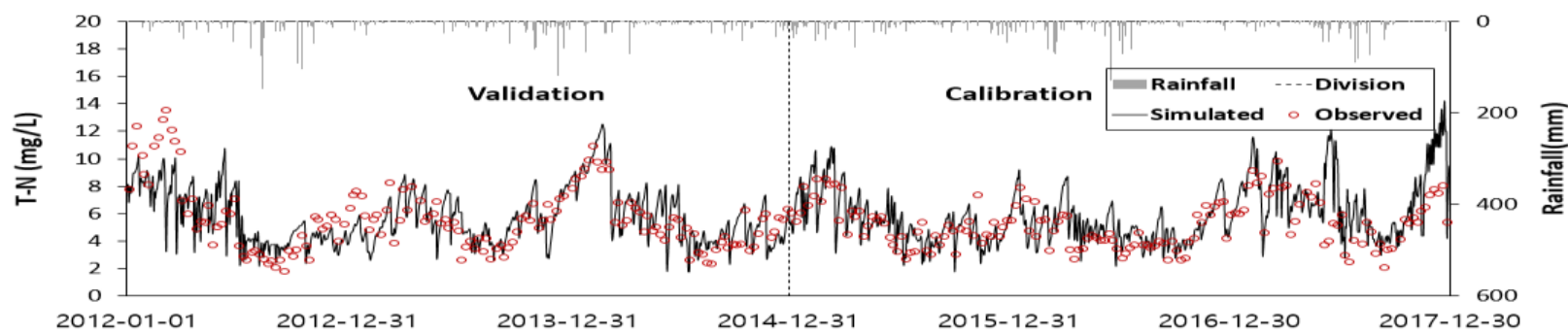

(a-3) T-N

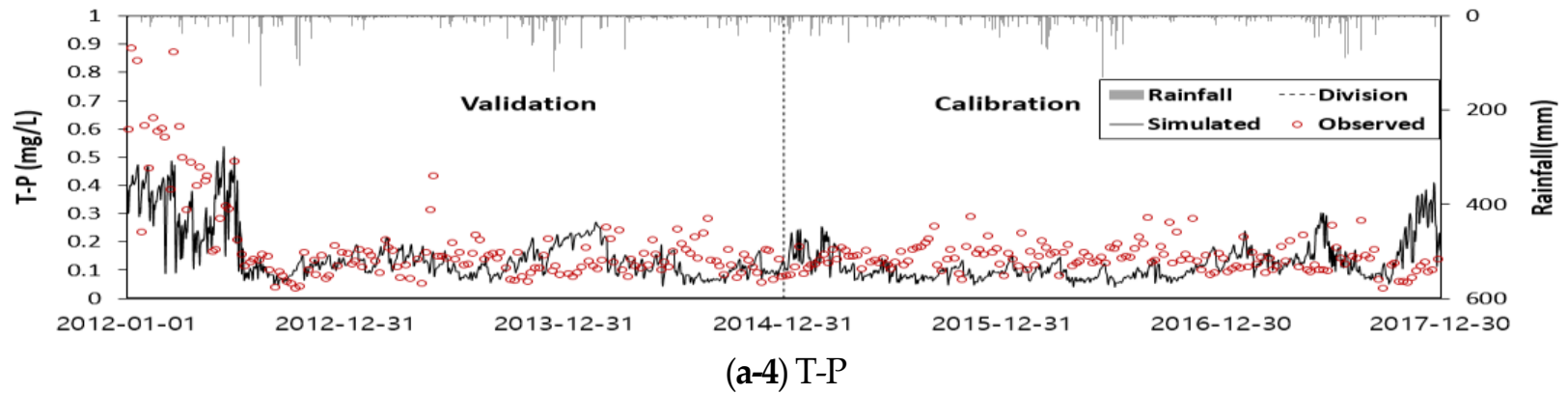

Figure 3. Simulated and measured values for major sub-areas of the Yeongsan River watershed (Section D).

The results show that all of the simulated flow and water quality (BOD, T-N, and $\mathrm{T}$-P) parameters of four-sub-areas have $\mathrm{R}^{2}$ values of more than 0.6 . Some were found to be fair based on the average relative error [25], but most were found to be good or higher, indicating that the parameters were appropriately calibrated and validated. As shown in Table 7 , the simulated values appropriately predicted the measured values. 
Table 7. Model validation and calibration results.

\begin{tabular}{|c|c|c|c|c|c|c|c|}
\hline \multirow{3}{*}{ Section } & \multirow{3}{*}{$\begin{array}{l}\text { Evaluation } \\
\text { Item }\end{array}$} & \multirow{3}{*}{$\begin{array}{c}\text { Analysis } \\
\text { Year }\end{array}$} & \multirow{2}{*}{\multicolumn{2}{|c|}{ Flow $\left(\mathrm{m}^{2} / \mathrm{s}\right)$}} & \multicolumn{3}{|c|}{ Water Quality (mg/L) } \\
\hline & & & & & BOD & T-N & T-P \\
\hline & & & R2 & \%diff. & & \%diff. & \\
\hline \multirow{2}{*}{$\begin{array}{c}\text { A } \\
\text { (Samji) }\end{array}$} & Validation & ‘08-’12 & $\begin{array}{c}0.74 \\
\text { (Good) }\end{array}$ & $\begin{array}{c}7.06 \\
\text { (Very Good) }\end{array}$ & - & - & - \\
\hline & Calibration & ‘13-’17 & $\begin{array}{c}0.76 \\
\text { (Good) }\end{array}$ & $\begin{array}{c}7.25 \\
\text { (Very Good) }\end{array}$ & - & - & - \\
\hline \multirow{2}{*}{$\begin{array}{c}\text { C } \\
\text { (Nampyeong, } \\
\text { Jiseok } \\
\text { stream 2) }\end{array}$} & Validation & ‘08-’12 & $\begin{array}{c}0.72 \\
\text { (Good) }\end{array}$ & $\begin{array}{c}0.93 \\
\text { (Very Good) }\end{array}$ & $\begin{array}{l}-23.88 \\
\text { (Good) }\end{array}$ & $\begin{array}{c}-9.3 \\
\text { (Very Good) }\end{array}$ & $\begin{array}{c}-0.89 \\
\text { (Very Good) }\end{array}$ \\
\hline & Calibration & ‘13-’17 & $\begin{array}{c}0.82 \\
\text { (Very Good) }\end{array}$ & $\begin{array}{c}9.50 \\
\text { (Very Good) }\end{array}$ & $\begin{array}{c}16.08 \\
\text { (Good) }\end{array}$ & $\begin{array}{c}1.75 \\
\text { (Very Good) }\end{array}$ & $\begin{array}{c}6.42 \\
\text { (Very Good) }\end{array}$ \\
\hline \multirow{2}{*}{$\begin{array}{c}\text { D } \\
\text { (Yeongbon B) }\end{array}$} & Validation & ‘12-’14 & $\begin{array}{c}0.79 \\
\text { (Good) }\end{array}$ & $\begin{array}{c}6.11 \\
\text { (Very Good) }\end{array}$ & $\begin{array}{c}16.4 \\
\text { (Good) }\end{array}$ & $\begin{array}{c}-0.38 \\
\text { (Very Good) }\end{array}$ & $\begin{array}{c}20.89 \\
\text { (Good) }\end{array}$ \\
\hline & Calibration & ‘15-’17 & $\begin{array}{c}0.76 \\
(\text { Good })\end{array}$ & $\begin{array}{c}-0.94 \\
\text { (Very Good) }\end{array}$ & $\begin{array}{l}26.73 \\
\text { (Fair) }\end{array}$ & $\begin{array}{c}-14.96 \\
\text { (Very Good) }\end{array}$ & $\begin{array}{c}19.94 \\
\text { (Good) }\end{array}$ \\
\hline \multirow{2}{*}{$\begin{array}{c}\text { D } \\
(\text { Yeongbon C) }\end{array}$} & Validation & ‘08-’12 & $\begin{array}{c}0.74 \\
\text { (Good) }\end{array}$ & $\begin{array}{c}9.32 \\
\text { (Very Good) }\end{array}$ & $\begin{array}{c}14.09 \\
\text { (Very Good) }\end{array}$ & $\begin{array}{c}4.99 \\
\text { (Very Good) }\end{array}$ & $\begin{array}{c}17.17 \\
\text { (Good) }\end{array}$ \\
\hline & Calibration & ‘13-’17 & $\begin{array}{c}0.78 \\
\text { (Good) }\end{array}$ & $\begin{array}{l}-12.58 \\
\text { (Good) }\end{array}$ & $\begin{array}{l}25.45 \\
\text { (Fair) }\end{array}$ & $\begin{array}{l}-29.4 \\
\text { (Fair) }\end{array}$ & $\begin{array}{c}17.23 \\
\text { (Good) }\end{array}$ \\
\hline
\end{tabular}

\subsection{Water Circulation-Nonpoint Pollution Status of the Watershed}

Based on the calibrated and validated HSPF model, impervious area rates for each small sub-area (as of 2017), 10-year-averaged nonpoint source load per unit areas $\left(\mathrm{kg} / \mathrm{km}^{2} / \mathrm{yr}\right)$, and water circulation rates (\%) under the 10-year long-term rainfall condition were analyzed for the Yeongsan River watershed. In addition, the water circulation rates (\%) under the $25.4 \mathrm{~mm}$ short-term rainfall condition were also analyzed by referring to the water circulation rate calculation method (NRCS-CN method). Figure 4 and Table 8 shows the analysis results.

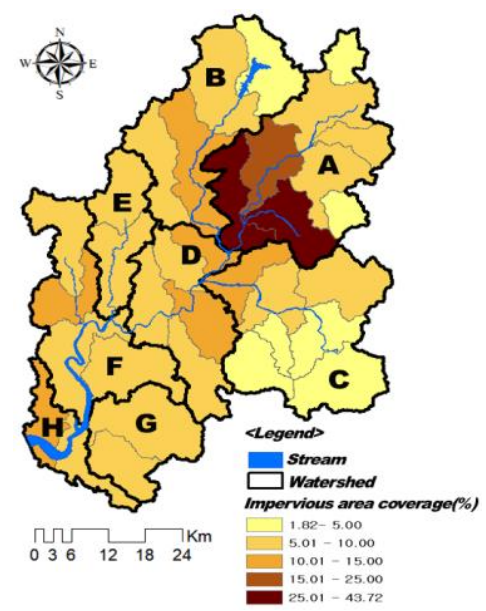

(a) Impervious area rates $(\%)$

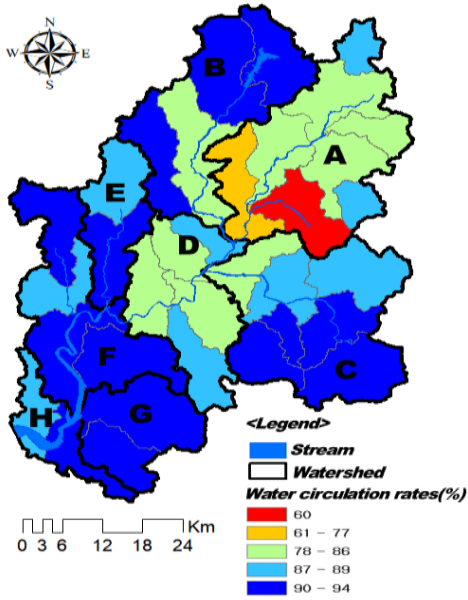

(b) Water circulation rates(\%)

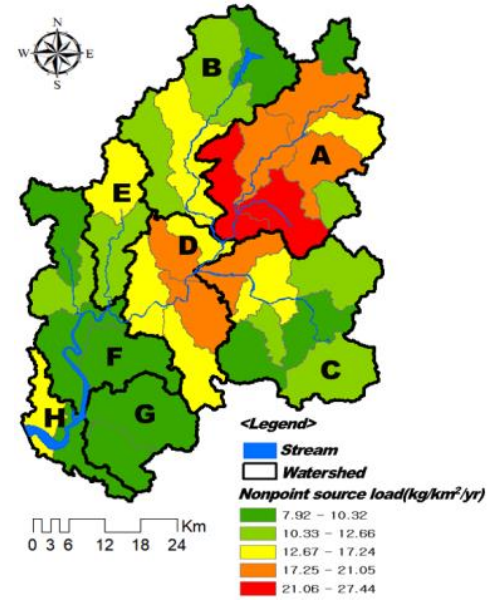

(c) Nonpoint source $\operatorname{Load}\left(\mathrm{kg} / \mathrm{km}^{2} / \mathrm{yr}\right)$

Figure 4. Water circulation-nonpoint pollution status evaluation results. (a) Impervious area rates (\%), (b) Water circulation rates (\%), and (c) Nonpoint source load $\left(\mathrm{kg} / \mathrm{km}^{2} / \mathrm{yr}\right)$. 
Table 8. Results of evaluating the current status of water circulation and nonpoint pollution.

\begin{tabular}{|c|c|c|c|}
\hline $\begin{array}{c}\text { Medium } \\
\text { Influence Area }\end{array}$ & $\begin{array}{c}\text { Impervious Area Rate } \\
(\%)\end{array}$ & Water Circulation Rate (\%) & $\begin{array}{l}\text { Nonpoint Source Load } \\
\left(\mathrm{kg} / \mathrm{km}^{2} / \mathrm{yr}\right)\end{array}$ \\
\hline A & 18.47 & 79.52 & 18.47 \\
\hline $\mathrm{B}$ & 7.05 & 89.61 & 11.57 \\
\hline $\mathrm{C}$ & 5.86 & 89.22 & 12.52 \\
\hline $\mathrm{D}$ & 10.38 & 84.87 & 17.68 \\
\hline E & 7.4 & 88.72 & 13.63 \\
\hline $\mathrm{F}$ & 8.38 & 89.73 & 10.16 \\
\hline G & 7.45 & 90.71 & 9.75 \\
\hline $\mathrm{H}$ & 9.82 & 88.68 & 11.72 \\
\hline
\end{tabular}

For the impervious area, the Yeongsan River watershed showed an average of 9.72\%; medium-sized sub-area A exhibited the highest value of $18.47 \%$. For the small sub-areas, the impervious area exceeded 25\% for Gwangju Stream and Hwangryong River Joint (43.72 and $28.75 \%$, respectively). This is because Gwangju Metropolitan City is located in sub-area A and includes many industrial complexes. This region was designated (in 2007) as a nonpoint management area because it had a population of more than one million and a BOD nonpoint contribution rate of higher than $50 \%$. Management countermeasures were established from 2007 to 2017, and nonpoint pollution reduction projects were performed. In particular, it was selected as a water circulation city in 2016 and a master plan was established (in 2018). Currently, focus is given to the recovery of the water circulation rate through improvements to impervious areas by applying the LID technique [31].

The average nonpoint source load was $14.14 \mathrm{~kg} / \mathrm{km}^{2} / \mathrm{yr}$, and sub-area A with its large impervious area exhibited the highest nonpoint source load of $18.47 \mathrm{~kg} / \mathrm{km}^{2} / \mathrm{yr}$. This appears to be due to the large number of urban nonpoint sources caused by an increase in the proportion of building sites. Sub-area D (impervious area rate of $10.38 \%$ ), which is downstream of sub-area A, exhibited the second highest nonpoint source load $\left(17.68 \mathrm{~kg} / \mathrm{km}^{2} / \mathrm{yr}\right)$, suggesting that it is impacted by upstream areas.

Sub-area A also exhibited a low water circulation rate (79.52\%) compared with the average water circulation rate of the watershed (86\%). It is analyzed as the cause of urbanization where Gwangju Metropolitan City is located and industrial and residential complexes are concentrated. Sub-area $\mathrm{D}$, which has the second highest impervious area rate, also exhibited a water circulation rate $(84.87 \%)$ lower than that of the average. Other areas showed high water circulation rates as most are characterized by forests, fields, and farmland.

\subsection{Water Circulation Structure and Water Quality Improvement through Scenario Analysis}

Figures 5-7 show the results of analyzing the direct runoff, base flow, and nonpoint source load reduction effect per unit area due to the improvement in the water circulation structure of the Yeongsan River watershed for each impervious area reduction scenario (Table 4). Direct runoff and nonpoint source load decreased from scenario S2 to S6. In contrast, the base flow increased. These analyses show the same trend as the result of increasing direct runoff and nonpoint source load according to the increase in impervious area suggested by [4]. Additionally, it is similar to the result that changes in land use and an increase in impervious area adversely affect river water quality and have a positive correlation with direct runoff $[32,33]$. Finally, urbanization and climate change will double the total phosphorus emission load in urban watersheds in northern Italy. However, the result that the emission load is expected to recover to the current level if the current impervious area is reduced by about 15\% [34] supports the results of this paper. In the Yeongsan River watershed, sub-area A, which includes small areas with an impervious area rate of more than $25 \%$, exhibited changes under scenarios S2 to S6. For sub-area D, changes occurred only under scenarios S5 and S6. For the other medium-sized areas, the impervious area rate was between $2 \%$ and $15 \%$ and only scenario 56 had an effect. 


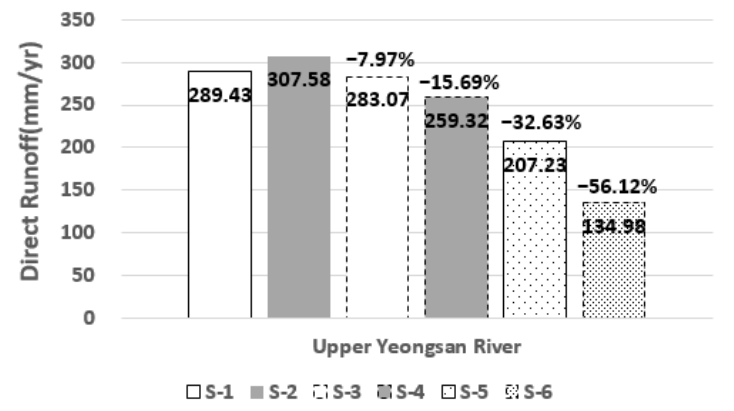

(a) Upper Yeongsan River (A)

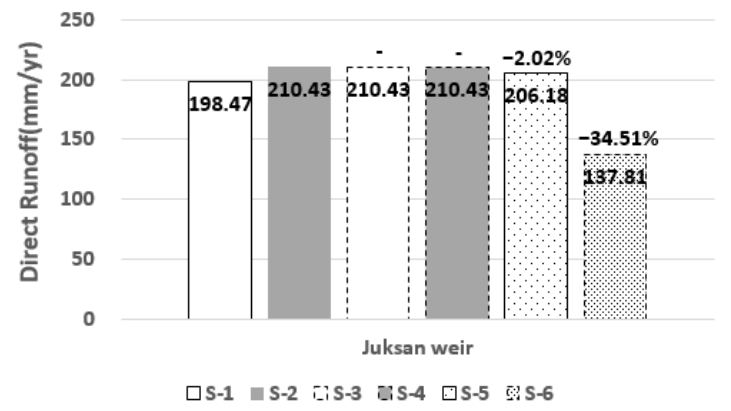

(b) Juksan Weir (D)

Figure 5. Water circulation structure improvement effect by scenario (direct runoff, mm/yr). (a) Upper Yeongsan River (A), and (b) Juksan Weir (D).

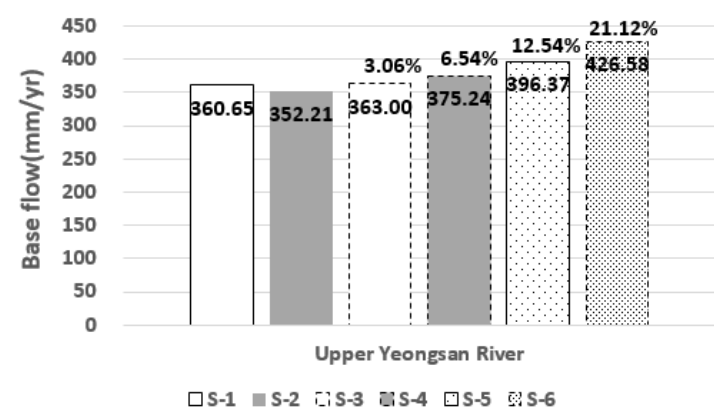

(a) Upper Yeongsan River (A)

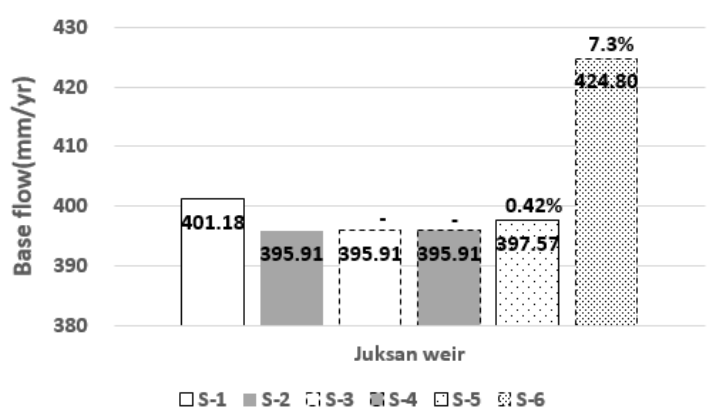

(b) Juksan Weir (D)

Figure 6. Water circulation structure improvement effect by scenario (base flow, mm/yr). (a) Upper Yeongsan River (A), and (b) Juksan Weir (D).

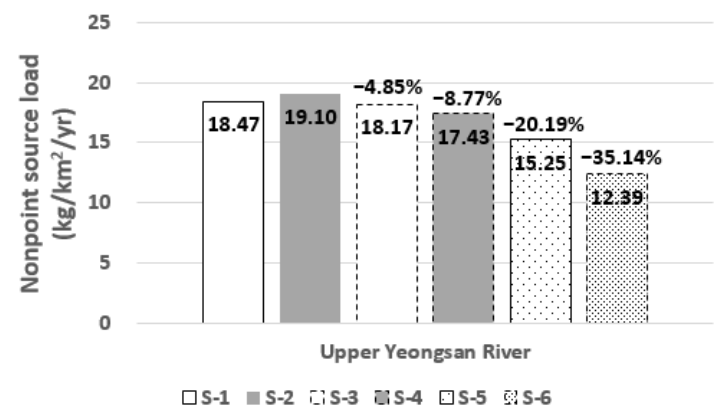

(a) Upper Yeongsan River (A)

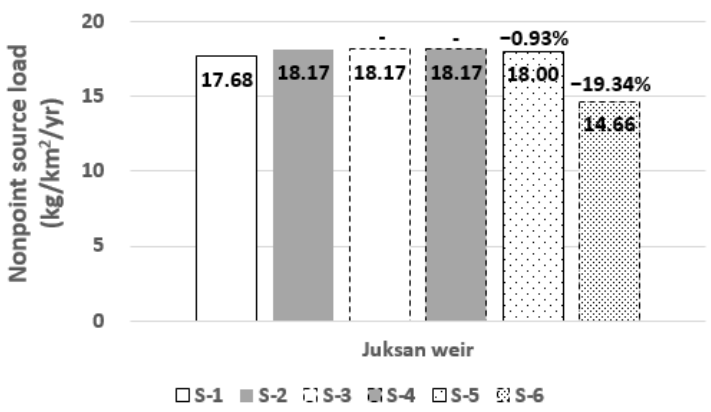

(b) Juksan Weir (D)

Figure 7. Water circulation structure improvement effect by scenario (nonpoint load, $\mathrm{kg} / \mathrm{km}^{2} / \mathrm{yr}$ ). (a) Upper Yeongsan River (A), and (b) Juksan Weir (D).

Middle area A exhibited a direct runoff of $307.58 \mathrm{~mm} / \mathrm{yr}$ under scenario S2, which was higher than those of other medium-sized sub-areas (108.82 to $210.43 \mathrm{~mm} / \mathrm{yr}$ ). This appears to be because the average impervious area rate was as high as $17.05 \%$; some small sub-areas had even higher rates, including Gwangju Stream (48.97\%) and Hwangryong River Joint (30.25\%). The high proportions of building sites and roads due to urbanization were identified as a cause. In terms of the improvement effect, a reduction efficiency of up to $56 \%$ was observed for sub-area A under scenarios S3 to S6, and reduction efficiencies of $16 \%$ to $40 \%$ were observed under scenarios S5 and S6 for other medium-sized sub-areas.

The base flow showed a tendency to increase in contrast to the decreasing tendency of the direct runoff. This is because the flow absorbed by soil increased owing to the recovery of the pervious area through an improvement in the impervious area rate. Sub-area A 
exhibited a base flow of $352.21 \mathrm{~mm} / \mathrm{yr}$, which was somewhat low compared with those of other medium-sized sub-areas (299.44 to $508.85 \mathrm{~mm} / \mathrm{yr}$ ). This appears to be due to the high direct runoff under the influence of small areas with an impervious area rate of more than $25 \%$. In terms of the improvement effect, the base flow increased by up to $21 \%$ for sub-area A under scenarios S3 to S6, and by $0.13 \%$ to $7.3 \%$ under scenarios S5 and S6 for the other medium sized sub-areas, resulting in somewhat low efficiency.

The nonpoint source load shows the same trend as the result of the direct runoff. It was found to be high in the sub-area with a high impervious area. It decreased from S2 to S6. Sub-area A exhibited a value of $19.1 \mathrm{~kg} / \mathrm{km}^{2} / \mathrm{yr}$, which was higher than the values of other medium sized sub-areas ( 9.9 to $18.17 \mathrm{~kg} / \mathrm{km}^{2} / \mathrm{yr}$ ). In terms of the improvement effect owing to the application of the impervious area reduction scenarios, a reduction efficiency of up to 35\% was observed for sub-area A under scenarios S3 to S6, and a reduction efficiency of $0.73 \%$ to $23.7 \%$ was observed for the other medium sized sub-areas.

To set medium- and long-term water circulation management goals, the water circulation improvement effect was analyzed for Gwangju Stream and Hwangryong River Joint (Figure 8), both small sub-areas within the larger sub-area A; the impervious area rates exceeded $25 \%$ under the $\mathrm{S} 2$ condition. According to the impervious area reduction scenarios, it was found that direct runoff and nonpoint source load increased, whereas the base flow increased.
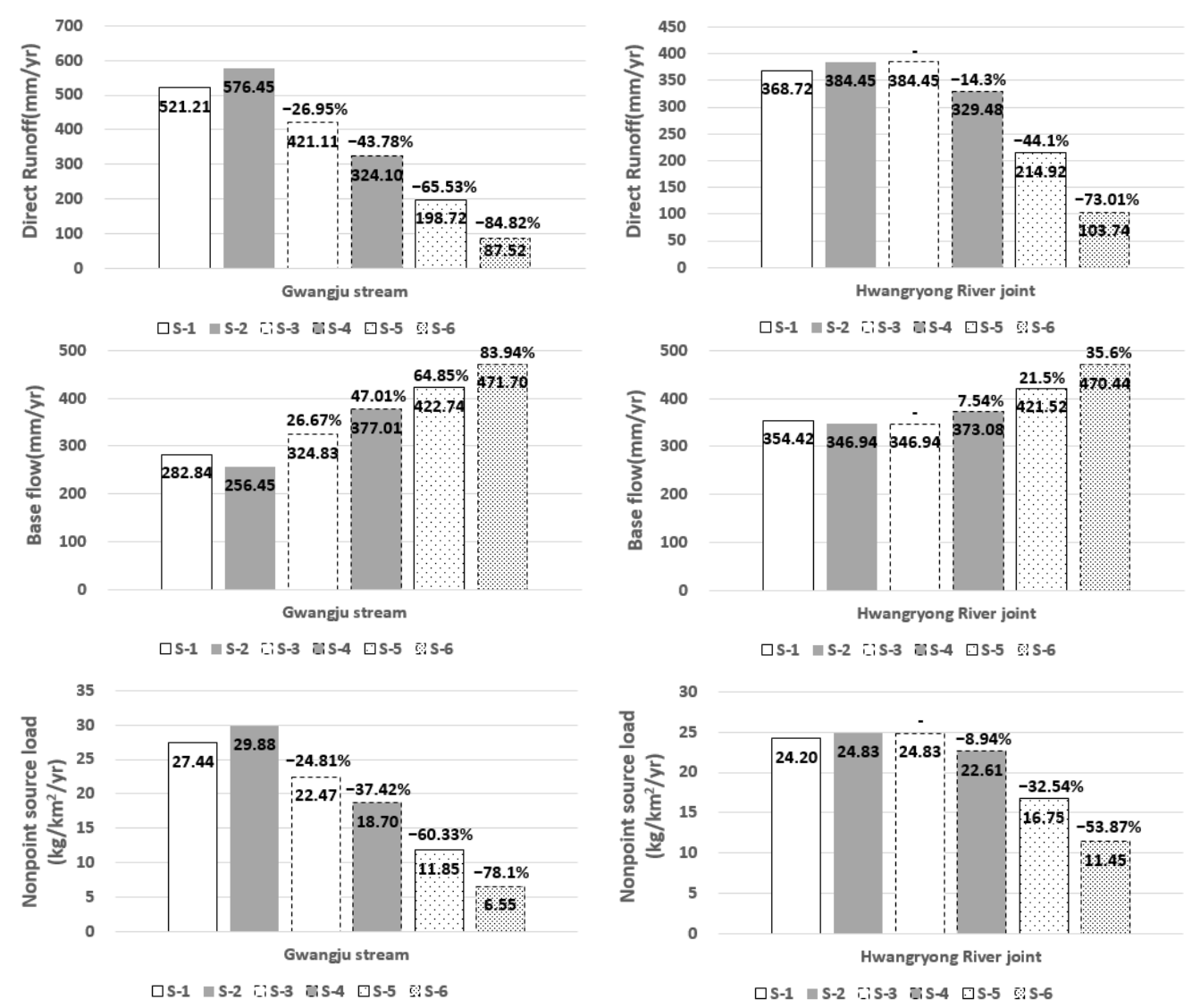

(a) Gwangju Stream

(b) Hwangryong River Joint

Figure 8. Water circulation structure improvement effect by scenario (small sub-areas). (a) Gwangju Stream, and (b) Hwangryong River Joint.

Gwangju Stream exhibited a direct runoff reduction effect of up to $85 \%$ and the Hwangryong River Joint exhibited a direct runoff reduction effect of up to $73 \%$, respectively. The base flow was found to increase by $84 \%$ in scenario 56 . The nonpoint source load was reduced by up to $78 \%$ and $54 \%$ for Gwangju Stream and by 35\% for the Hwangryong River Joint. This is because the impervious area was changed to a pervious area under scenarios 
S3 to S6 and thus more rainfall penetrated into the soil during the rainy season. It also appears to be because the water that penetrated underground slowly flowed into the rivers in the form of base flow throughout the year.

\subsection{Medium- and Long-Term Water Circulation Management Goals}

Based on the principles for setting medium- and long-term water circulation management goals for nonpoint pollution management, the medium-term management target period was set to 2025 and the long-term management target period was set to 2065. After predicting the increase in the building area until 2025, two small sub-areas with severe urbanization within the Yeongsan River watershed (Gwangju Stream and Hwangryong River Joint) were selected for analysis.

Owing to the high urbanization rate, impervious area rates of between $30 \%$ and $49 \%$ are predicted in 2025 , significantly higher than the watershed average of $10.6 \%$. The water circulation rate under the short-term rainfall event condition was found to be between $56 \%$ and $70 \%$, lower than the average of $86 \%$.

Therefore, in the case of long-term goals for small areas with a high urbanization rate, goals were set such that the 10-year-averaged nonpoint source load could be reduced by approximately $9 \%$ to $37 \%$ based on the 2025 predictions; simultaneously, the direct runoff could be reduced by $14 \%$ to $44 \%$. To achieve these goals, the impervious area rate management goal was set to $25 \%$ and the water circulation rate management goal was set to at least $74 \%$ for each small area (Table 9 ). In the case of medium-term goals, investment plans to improve the water circulation of the Yeongsan River watershed were considered. The impervious area rate management goals chosen $(48.76 \%$ and $30.16 \%$ for Gwangju Stream and Hwangryong River Joint, respectively) could reduce the nonpoint source load by $0.13 \%$ to $0.33 \%$ and direct runoff by $0.24 \%$ to $0.38 \%$; the water circulation rate management goals were set to $75.07 \%$ and $74.65 \%$, respectively (Table 9 ). For the remaining small sub-areas where the urbanization rate is relatively lower (impervious area rate of less than $25 \%$ based on S2), the medium- and long-term goals were set to maintain the current impervious area rate and water circulation rate but to consider naturally increased development. Practical impervious area reduction goals could not be allocated owing to realistic problems, such as budget restrictions.

Table 9. Medium- and long-term water circulation management goals in the Yeongsan River watershed (sub-area A).

\begin{tabular}{|c|c|c|c|c|}
\hline Category & Small Sub-Areas & Future Prediction $\left(S 2,{ }^{\prime} 25\right)$ & Medium-Term Goal ('25) & Long-Term Goal (S4,'65) \\
\hline \multirow{2}{*}{$\begin{array}{l}\text { Direct runoff } \\
(\mathrm{mm} / \mathrm{yr})\end{array}$} & Gwangju Stream & $\begin{array}{c}576.45 \\
(-)\end{array}$ & $\begin{array}{c}574.25 \\
(\mathbf{\nabla} 0.38 \%)\end{array}$ & $\begin{array}{c}324.1 \\
(\mathbf{\nabla} 43.78 \%)\end{array}$ \\
\hline & Hwangryong River Joint & $\begin{array}{c}384.45 \\
(-)\end{array}$ & $\begin{array}{c}383.52 \\
(\boldsymbol{\nabla} 0.24 \%)\end{array}$ & $\begin{array}{c}329.48 \\
(\boldsymbol{\nabla} 14.3 \%) \\
\end{array}$ \\
\hline \multirow{2}{*}{ Base flow (mm/yr) } & Gwangju Stream & $\begin{array}{c}256.45 \\
(-)\end{array}$ & $\begin{array}{c}257.49 \\
(\boldsymbol{\nabla} 0.41 \%)\end{array}$ & $\begin{array}{c}377.01 \\
(\mathbf{\nabla} 47.01 \%)\end{array}$ \\
\hline & Hwangryong River Joint & $\begin{array}{c}346.94 \\
(-)\end{array}$ & $\begin{array}{c}347.38 \\
(\Delta 0.13 \%) \\
\end{array}$ & $\begin{array}{c}373.08 \\
(\mathbf{\Delta} 7.54 \%) \\
\end{array}$ \\
\hline \multirow{2}{*}{$\begin{array}{l}\text { Nonpoint source load } \\
\left(\mathrm{kg} / \mathrm{km}^{2} / \mathrm{yr}\right)\end{array}$} & Gwangju Stream & $\begin{array}{c}29.88 \\
(-)\end{array}$ & $\begin{array}{c}29.79 \\
(\Delta 0.33 \%)\end{array}$ & $\begin{array}{c}18.7 \\
(\mathbf{v} 37.42 \%)\end{array}$ \\
\hline & Hwangryong River Joint & $\begin{array}{c}24.83 \\
(-)\end{array}$ & $\begin{array}{c}24.79 \\
(\mathbf{v} 0.15 \%)\end{array}$ & $\begin{array}{c}22.61 \\
(\mathbf{\nabla} 8.94 \%)\end{array}$ \\
\hline \multirow{2}{*}{ Impervious area rate $(\%)$} & Gwangju Stream & 48.97 & 48.76 & 25.00 \\
\hline & Hwangryong River Joint & 30.25 & 30.16 & 25.00 \\
\hline \multirow{2}{*}{ Water circulation rate $(\%)$} & Gwangju Stream & 55.66 & 55.83 & 75.07 \\
\hline & Hwangryong River Joint & 70.43 & 70.50 & 74.65 \\
\hline
\end{tabular}




\section{Conclusions}

This study aimed to construct an evaluation system for setting water circulation management goals to address increases in the impervious area. The HSPF watershed model was applied to analyze the flow and pollutant loads of a watershed. The evaluation of the watershed status was conducted by applying impervious area reduction scenarios and analyzing the water circulation structure (impervious area, direct runoff, base flow, nonpoint source load, and water circulation rate) of the watershed. Finally, an attempt was made to set medium- and long-term water circulation management goals for areas with a high impervious area rate. The results of this study are as follows.

Owing to the increased impervious area in the Yeongsan River watershed, seven small sub-areas exhibited impervious area rates of between $0 \%$ and $5 \%, 25$ had rates between $5 \%$ and $25 \%$, and two had rates of more than $25 \%$. The upper Yeongsan River (medium-sized sub-area A) exhibited an impervious area rate of $18.47 \%, 1.9$ times higher than the average of the watershed $(9.72 \%)$. This appears to reflect the high level of urban and industrial development in Gwangju Metropolitan City.

The current water circulation rate of sub-area A (which is highly urbanized) was found to range from $59 \%$ to $88 \%$, and increased to between $75 \%$ and $88 \%$ when the impervious area rate was reduced by up to $25 \%$ under the water circulation structure improvement scenarios. While this process is ongoing, it is practically impossible to sharply reduce the impervious area rate over areas such as this. Therefore, it is necessary to apply the LID technique for public facilities or development projects over a certain scale.

The use of the nonpoint pollution-water circulation status prediction/evaluation system constructed in this study will make it possible to set goals for medium and small areas with a high urbanization rate using a unified method across the country. However, this requires some improvements. The achievement rate for the water circulation management goal was found to be somewhat low. This appears to be because the budget (Table 5) was set to be too low compared with the watershed area. In addition, more effort is also required in terms of policies. It is necessary to prepare grounds for systematic water circulation management, including water circulation goals (impervious area rate and water circulation rate), through the third comprehensive countermeasures for nonpoint source management (2021 to 2025), which is being established by the ME. In addition, it is necessary to manage urban areas with a large impervious area by designating them as nonpoint pollution management areas and to prevent indiscriminate urban development and damage to forests and fields. Through the results of $[35,36]$, flood occurrence in urban areas can be analyzed through the flow of fluids according to changes in rivers and waterways and changes in trees in the river ecosystem. For new cities, it is necessary to introduce a water circulation system that can improve rainwater penetration and recharge by introducing the LID technique and activating preemptive water circulation. LID technology has been widely applied to restore the water quality environment before development to reduce impervious areas. A study was conducted on the type, number, and arrangement of LID facilities optimized for regional characteristics. However, it is expected that the effect of LID will be difficult in studies on the effect of reducing emissions by applying LID facilities [37]. Therefore, it is necessary to study the effect analysis according to the optimal LID installation through scenario analysis.

To consider artificial water circulation (e.g., the reuse of pipes and sewage treatment plants) in the future, it will be necessary to conduct further research on setting water circulation goals by separating urban watersheds from watersheds combining cities and agriculture in the currently constructed model.

Author Contributions: All authors contributed meaningfully to this study. Conceptualization, J.M.L. and M.P.; methodology, J.M.L., M.P. and B.K.P.; software, J.M.L.; validation, J.M.L.; formal analysis, J.M.L.; investigation, J.M.L., J.C. and J.K.; resources, J.M.L., J.C. and J.K.; writing-original draft preparation, J.M.L.; writing-review and editing, J.M.L.; visualization, J.M.L., J.C. and J.K.; supervision, B.K.P.; project administration, K.K. and Y.K. All authors have read and agreed to the published version of the manuscript. 
Funding: Not applicable.

Institutional Review Board Statement: Not applicable.

Informed Consent Statement: Not applicable.

Data Availability Statement: Not applicable.

Acknowledgments: This work was supported by a grant from the National Institute of Environmental Research (NIER), funded by the Ministry of Environment (ME) of the Republic of Korea (NIER-2019-01-035).

Conflicts of Interest: The authors declare no conflict of interest.

\section{References}

1. National Institute of Environmental Research (NIER). A study on the Policy Implementation and Evaluation System for Achieving Hydrologic Cycle Target; NIER-SP2020-155; National Institute of Environmental Research: Incheon, Korea, 2020.

2. Carlson, T.N.; Arthur, S.T. The impact of land use-Land cover changes due to urbanization on surface microclimate and hydrology: A satellite perspective. Glob. Planet Change 2000, 25, 49-65. [CrossRef]

3. Li, C.; Sun, G.; Caldwell, P.V.; Cohen, E.; Fang, Y.; Zhang, Y.; Oudin, L.; Sanchez, G.M.; Meentemeyer, R.K. Impacts of urbanization on watershed water balances across the conterminous United States. Water Resour. Res. 2020, 56, e2019WR02657. [CrossRef]

4. Lee, J.M.; Ryu, J.; Choi, J.; Park, J.; Kim, J.; Shin, D.S.; Lee, J. Predicting the effect of impervious area change on water circulation rate in the Geum River watershed using HSPF modeling. Desalination Water Treat. 2020, 200, 337-350. [CrossRef]

5. Ahamed, A.; Bolten, J.D. A MODIS-based automated flood monitoring system for southeast Asia. Int. J. Appl. Earth Obs. Geoinf. 2017, 61, 104-117. [CrossRef]

6. Schmitt, T.G.; Thomas, M.; Ettrich, N. Analysis and modeling of flooding in urban drainage systems. J. Hydrol. 2004, 299, 300-311. [CrossRef]

7. Kubal, C.; Haase, D.; Meyer, V.; Scheuer, S. Integrated urban flood risk assessment-adapting a multicriteria approach to a city. Nat. Hazards Earth Syst. Sci. 2009, 9, 1881-1895. [CrossRef]

8. Oudin, L.; Salavati, B.; Furusho-Percot, C.; Ribstein, P.; Saadi, M. Hydrological impacts of urbanization at the catchment scale. J. Hydrol. 2018, 559, 774-786. [CrossRef]

9. National Institute of Environmental Research (NIER). Customized Policy Support for Nonpoint Pollution Management and Water Circulation Improvement ( V); NIER-RP2020-289; National Institute of Environmental Research: Incheon, Korea, 2020.

10. Du, S.; Shi, P.; Van Rompaey, A.; Wen, J. Quantifying the impact of impervious surface location on flood peak discharge in urban areas. Nat. Hazards 2015, 76, 1457-1471. [CrossRef]

11. Bhaskar, A.S.; Hogan, D.M.; Stacey, A. Archfield. Urban base flow with low impact development. Hydrol. Process. 2016, 30, 3156-3171. [CrossRef]

12. Schoener, G. Urban runoff in the U.S. southwest: Importance of impervious surfaces for small-storm hydrology. J. Hydrol. Eng. 2018, 23. [CrossRef]

13. Apollonio, C.; Balacco, G.; Novelli, A.; Tarantino, E.; Piccinni, A.F. Land use change impact on flooding areas: The case study of Cervaro Basin (Italy). Sustainability 2016, 8, 996. [CrossRef]

14. Zhang, C.; Li, Y. Rural planning based on landscape information chain theory: A case study of Jiabi Village in Maoba County, Lichuan City. J. Landsc. Res. Cranston 2018, 10, 21-24.

15. Kim, H.; Jeong, H.; Jeon, J.; Bae, S. The impact of impervious surface on water quality and its threshold in Korea. Water 2016, 8 , 111. [CrossRef]

16. Luo, K.; Hu, X.; He, Q.; Wu, Z.; Cheng, H.; Hu, Z.; Mazumder, A. Impacts of rapid urbanization on the water quality and macroinvertebrate communities of streams: A case study in Liangjiang New Area. China Sci. Total. Environ. 2018, 621, 1601-1614. [CrossRef]

17. Luo, Y.; Zhao, Y.; Yang, K.; Chen, K.; Pan, M.; Zhou, X. Dianchi Lake watershed impervious surface area dynamics and their impact on lake water quality from 1988 to 2017. Environ. Sci. Pollut. Res. 2018, 25, 29643-29653. [CrossRef] [PubMed]

18. Ministry of Land, Transport and Maritime Affairs (MLTMA). The Basic Plan for Yeongsan River (Change); Ministry of Land Transport and Maritime Affairs: Sejong City, Korean, 2009.

19. Park, M.H.; Cho, H.L.; Koo, B.K. Estimation of pollution loads from the yeongsan river basin using a conceptual watershed model. J. Korea Soc. Water Environ. 2014, 30, 184-198. [CrossRef]

20. KEI (Korea Environment Institute). Research on Water Environment Management Plan in Yeongsan River Metropolitan Area; Korea Environment Institute: Sejong City, Korea, 2018.

21. National Institute of Environmental Research (NIER). Customized Policy Support for Nonpoint Pollution Management and Water Circulation Improvement(IV); NIER-RP2019-245; National Institute of Environmental Research: Incheon, Korea, 2019.

22. National Institute of Environmental Research (NIER). Study on Customized Policy Support for Nonpoint Source Pollution Management and Water Circulation Improvement (2); NIER-RP2017-301; National Institute of Environmental Research: Incheon, Korea, 2017. 
23. Albek, M.; Albek, E.A.; Goncu, S.; Uygun, B.S. Ensemble streamflow projections for a small watershed with HSPF model. Environ. Sci. Pollut. Res. 2019, 26, 36023-36036. [CrossRef]

24. Korea Environment Corporation (K-ECO). Study on Implementation and Operation Plan for Water Circulation Management of Watershed; Korea Environment Corporation: Incheon, Korea, 2018.

25. Donigian, A.S. Watershed model calibration and validation: The HSPF experience. Proc. Water Environ. Fed. 2002, 8, 44-73. [CrossRef]

26. Environmental Protection Agency (EPA). Lecture \#15, Watershed Model Calibration and Validation: Issues and Procedures; Environmental Protection Agency (EPA): Washington, DC, USA, 2011.

27. Soil Conservation Service (SCS). National Engineering Handbook, Section 4, Hydrology, Department of Agriculture; US Government Printing Office: Washington, DC, USA, 1972.

28. National Institute of Environmental Research (NIER). Customized Policy Support for Nonpoint Pollution Management and Water Circulation Improvement(III); NIER-RP2018-248; National Institute of Environmental Research: Incheon, Korea, 2018.

29. National Institute of Environmental Research (NIER). A Research on Control Targets and Strategies for Impervious Surface Management (I); NIER-SP2014-321; National Institute of Environmental Research: Incheon, Korea, 2014; pp. 66-68.

30. Scheler, T. The importance of imperviousness. Watershed Prot. Tech. 1994, 1, 100-111.

31. Kim, J.; Choi, J.; Lee, J.M.; Na, E.; Shin, D.S.; Lee, J.; Ryu, J. A study on the plan for selection of prioritization management area for reduction of non-point pollution in Gwangju Metropolitan City. J. Korea Environ. Policy Adm. Soc. 2019, 27, $189-214$.

32. Meierdiercks, K.L.; Kolozsvary, M.B.; Rhoads, K.P.; Golden, M.; McCloskey, N.F. The role of land surface versus drainage network characteristics in controlling water quality and quantity in a small urban watershed. Hydrol. Process. 2017, 31, 4384-4397. [CrossRef]

33. Wilson, C.O. Land use/land cover water quality nexus: Quantifying anthropogenic influences on surface water quality. Environ. Monit. Assess. 2015, 187, 424. [CrossRef]

34. Salerno, F.; Gaetano, V.; Gianni, T. Urbanization and climate change impacts on surface water quality: Enhancing the resilience by reducing impervious surfaces. Water Res. 2018, 144, 491-502. [CrossRef] [PubMed]

35. Lama, G.F.C.; Crimaldi, M.; Pasquino, V.; Padulano, R.; Chirico, G.B. Bulk drag predictions of riparian arundo donax stands through UAV-acquired multispectral images. Water 2021, 13, 1333. [CrossRef]

36. Pasquino, V.; Saulino, L.; Pelosi, A.; Saracino, A.; Chirico, G.B. Hydrodynamic behaviour of European black poplar (Populus nigra L.) under coppice management along Mediterranean river ecosystems. River Res. Appl. 2018, 34, 586-594. [CrossRef]

37. Kwak, D.; Kim, H.; Han, M. Runoff control potential for design types of low impact development in small developing area using XPSWMM. Procedia Eng. 2016, 154, 1324-1332. [CrossRef] 